\title{
Mono- and Binuclear Copper(II) and Nickel(II) Complexes with the 3,6-Bis(picolylamino)-1,2,4,5-Tetrazine Ligand
}

\author{
Oleh Stetsiuk $^{1}{ }^{\oplus}$, Abdelkrim El-Ghayoury ${ }^{1}\left(\mathbb{C}\right.$, Francesc Lloret ${ }^{2}$, Miguel Julve ${ }^{2, *}$ and Narcis Avarvari ${ }^{1, *(\mathbb{C})}$ \\ 1 Univ Angers, CNRS, MOLTECH-Anjou, SFR MATRIX, F-49000 Angers, France; \\ oleh.stetsiuk@polytechnique.edu (O.S.); abdelkrim.elghayoury@univ-angers.fr (A.E.-G.) \\ 2 Departament de Química Inorgànica, Instituto de Ciencia Molecular (ICMol), Universitat de València, \\ Catedrático José Beltrán 2, 46980 Paterna, Spain; Francisco.Lloret@uv.es \\ * Correspondence: Miguel.Julve@uv.es (M.J.); narcis.avarvari@univ-angers.fr (N.A.)
}

check for updates

Citation: Stetsiuk, O.; El-Ghayoury, A.; Lloret, F.; Julve, M.; Avarvari, N. Mono- and Binuclear Copper(II) and Nickel(II) Complexes with the 3,6Bis(picolylamino)-1,2,4,5-Tetrazine Ligand. Molecules 2021, 26, 2122. https://doi.org/10.3390/ molecules 26082122

Academic Editors: Pierre Audebert and Jean-Cyrille Hierso

Received: 16 March 2021

Accepted: 31 March 2021

Published: 7 April 2021

Publisher's Note: MDPI stays neutral with regard to jurisdictional claims in published maps and institutional affiliations.

Copyright: (C) 2021 by the authors. Licensee MDPI, Basel, Switzerland. This article is an open access article distributed under the terms and conditions of the Creative Commons Attribution (CC BY) license (https:// creativecommons.org/licenses/by/ $4.0 /)$.

\begin{abstract}
Four new compounds of formulas [Cu(hfac $\left.)_{2}(\mathrm{~L})\right](\mathbf{1}),\left[\mathrm{Ni}(\mathrm{hfac})_{2}(\mathrm{~L})\right](2),\left[\left\{\mathrm{Cu}(\mathrm{hfac})_{2}\right\}_{2}(\mu-\right.$ $\mathrm{L})] \cdot 2 \mathrm{CH}_{3} \mathrm{OH}$ (3) and $\left[\left\{\mathrm{Ni}(\mathrm{hfac})_{2}\right\}_{2}(\mu-\mathrm{L})\right] \cdot 2 \mathrm{CH}_{3} \mathrm{CN}$ (4) [Hhfac = hexafluoroacetylacetone and $\mathrm{L}=3,6$-bis(picolylamino)-1,2,4,5-tetrazine] have been prepared and their structures determined by $\mathrm{X}$ ray diffraction on single crystals. Compounds $\mathbf{1}$ and $\mathbf{2}$ are isostructural mononuclear complexes where the metal ions [copper(II) (1) and nickel(II) (2)] are six-coordinated in distorted octahedral $\mathrm{MN}_{2} \mathrm{O}_{4}$ surroundings which are built by two bidentate hfac ligands plus another bidentate $\mathrm{L}$ molecule. This last ligand coordinates to the metal ions through the nitrogen atoms of the picolylamine fragment. Compounds 3 and 4 are centrosymmetric homodinuclear compounds where two bidentate hfac units are the bidentate capping ligands at each metal center and a bis-bidentate L molecule acts as a bridge. The values of the intramolecular metal $\cdots$ metal separation are 7.97 (3) and $7.82 \AA$ (4). Static (dc) magnetic susceptibility measurements were carried out for polycrystalline samples 1-4 in the temperature range 1.9-300 K. Curie law behaviors were observed for $\mathbf{1}$ and $\mathbf{2}$, the downturn of $\chi_{M} T$ in the low temperature region for 2 being due to the zero-field splitting of the nickel(II) ion. Very weak $\left[J=-0.247(2) \mathrm{cm}^{-1}\right]$ and relatively weak intramolecular antiferromagnetic interactions $\left[J=-4.86(2) \mathrm{cm}^{-1}\right]$ occurred in 3 and 4 , respectively (the spin Hamiltonian being defined as $\boldsymbol{H}=-J \boldsymbol{S}_{1} \cdot \boldsymbol{S}_{2}$ ). Simple symmetry considerations about the overlap between the magnetic orbitals across the extended bis-bidentate L bridge in $\mathbf{3}$ and $\mathbf{4}$ account for their magnetic properties.
\end{abstract}

Keywords: 1,2,4,5-tetrazine; nitrogen ligands; nickel; copper; crystal structure determination; magnetic properties

\section{Introduction}

The 1,2,4,5-tetrazine (TTZ) ring [1,2], thanks to its substituent dependent fluorescent properties [3-6], electron withdrawing character, allowing access to stable radical anion species [7-9], and active role in the establishment of anion- $\pi$ interactions [10-14], has been considered as suitable platform for the attachment of coordinating groups towards multifunctional ligands and corresponding metal complexes [15,16]. Besides the possibility to access photoactive metal complexes [16], enhancement of the magnetic coupling between metal centers thanks to the bridging tetrazine radical anion can be achieved as well [17]. Accordingly, functionalization of TTZ in the positions 3 and 6 of the ring with nitrogen containing units allowed the preparation and use in various metal complexes of either ditopic and tetratopic ligands such as 3,6-(2'-dipyridyl)-TTZ [18,19], 3,6-dipyrimidyl-TTZ [20-24] and 3,6-(dipyrazolyl)-TTZ [25,26], or monotopic ligands, obtained from 3,6-dichloro-TTZ by nucleophilic substitution, such as dipicolylamine-TTZ-Cl [27], dipicolylamine-TTZtetrathiafulvalene [28] and dipicolylamine-TTZ-OMe [29]. Note that an interesting difference of the magnetic coupling between the metal centers in chloro-bridged dicobalt(II) and dimanganese(II) complexes with the dipicolylamine-TTZ-Cl ligand has been observed. 
Accordingly, antiferromagnetic coupling occurs in the latter, while the coupling is ferromagnetic in the cobalt(II) complex [27]. Although the magnetic interaction between the metal centers was not mediated by the tetrazine ring, these results highlight the opportunities arising from its use as a platform for functional ligands, affording complexes provided with interesting magnetic properties. Besides functionalization with dipicolylamine, the reaction of 3,6-dichloro-TTZ with 2-picolylamine $\left(2-\mathrm{PyCH}_{2} \mathrm{NH}_{2}\right)$ in methyl-t-butylether provided either mono(picolylamine)-TTZ-Cl (pica-TTZ-Cl) [30] or bis(picolylamine)-TTZ (bis(pica)-TTZ L) [31] (Scheme 1) depending on the reaction time and temperature.<smiles>Clc1nnc(NCc2ccccn2)nn1</smiles>

pica-TTZ-Cl

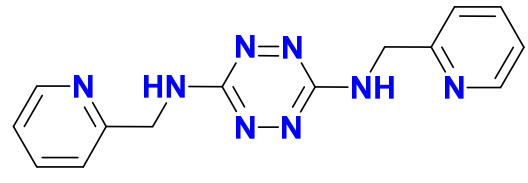

bis(pica)-TTZ (L)

Scheme 1. Picolylamine-1,2,4,5-tetrazine (TTZ) molecules; L was used as ligand in the present study.

Pica-TTZ-Cl proved its versatile coordination behavior as a neutral or monoanionic ligand in a series of copper(II) mononuclear and mixed-valence copper(II)/copper(I) binuclear complexes [30], while with ligand L we have previously reported the cobalt(II) complexes of the formula [Co(hfac) $\left.)_{2}(\mathrm{~L})\right] \cdot \mathrm{CH}_{3} \mathrm{CN}$ and $\left\{\left[\mathrm{Co}(\mathrm{hfac})_{2}(\mu-\mathrm{L})\right]\left[\mathrm{Co}(\mathrm{hfac})_{2}\left(\mathrm{CH}_{3} \mathrm{OH}\right)_{2}\right]\right\}_{\mathrm{n}}(\mathrm{hfac}$ = hexafluoroacetylacetonate), which have shown field-induced slow magnetic relaxation, indicative of the so-called single-ion magnet (SIM) behavior [31].

In the continuation of our research on tetrazine-based ligands and complexes, we report herein the synthesis, in-depth structural characterization and magnetic properties of mono- and binuclear copper(II) and nickel(II) complexes with the bis(pica)-TTZ ligand L.

\section{Results and Discussion}

\subsection{Synthesis and Characterization of TTZ-Based Complexes $\mathbf{1 - 4}$}

Since $\mathrm{L}$ is a ditopic ligand containing two chelating units, its reaction with metal centers could, in principle, lead to discrete mono- and binuclear metal complexes or coordination polymers, depending on the number of available coordination sites on the metal center. As mentioned above, in the course of a previous study [31] we indeed obtained a mononuclear cobalt(II) complex [Co(hfac $\left.)_{2}(\mathrm{~L})\right]$, where $\mathrm{L}$ acts as a monotopic chelating ligand, and a one-dimensional coordination polymer $\left[\mathrm{Co}(\mathrm{hfac})_{2}(\mu-\mathrm{L})\right]_{\mathrm{n}}$, in which $\mathrm{L}$ connects cobalt(II) centers through coordination of the pyridines only. We extend herein our study towards the paramagnetic centers copper(II) and nickel(II) by the use of the neutral $\left[\mathrm{M}(\mathrm{hfac})_{2}\right]$ precursors. First, reaction of $\mathrm{L}$ with one equivalent of $\left[\mathrm{M}(\mathrm{hfac})_{2}\right]$ afforded the mononuclear complexes $\left[\mathrm{Cu}(\mathrm{hfac})_{2}(\mathrm{~L})\right](\mathbf{1})$ and $\left[\mathrm{Ni}(\mathrm{hfac})_{2}(\mathrm{~L})\right](\mathbf{2})$ (Scheme 2) where $\mathrm{L}$ acts as a monotopic bidentate ligand thanks to its $\mathrm{N}_{\mathrm{Py}}$ and $\mathrm{N}_{\mathrm{amine}}$ atoms. In both complexes, the ligand remains in its amino form and not amido, as already observed with the pica-TTZ- $\mathrm{Cl}$ ligand and $\left[\mathrm{Cu}(\mathrm{hfac})_{2}\right]$ fragment [30].

This can be very likely explained by the lower acidity of the amino groups in $L$ than in pica-TTZ- $\mathrm{Cl}$, where the presence of the $\mathrm{Cl}$ substituent in the para position enhances the acidity of the NH group in the latter. On the other hand, reaction of $L$ with an excess of $\left[\mathrm{M}(\mathrm{hfac})_{2}\right]$ leads to the binuclear complexes $\left[\left\{\mathrm{Cu}(\mathrm{hfac})_{2}\right\}_{2}(\mu-\mathrm{L})\right](3)$ and $\left[\left\{\mathrm{Ni}(\mathrm{hfac})_{2}\right\}_{2}(\mu-\mathrm{L})\right]$ (4) (Scheme 2) in which both picolylamino groups chelate the metal centers in a bidentate mode.

The mono- or binuclear nature of complexes 1-4 is definitely evidenced by singlecrystal X-ray diffraction analysis. The best quality crystals for the copper(II) complexes 1 and 3 were obtained from methanol, while acetonitrile was successfully used for the nickel(II) complexes $\mathbf{2}$ and $\mathbf{4}$. Complexes $\mathbf{1}$ and $\mathbf{2}$ are isostructural and crystallize in the monoclinic system, space group $P 2_{1} / \mathrm{n}$, with one molecule of complex in the asymmetric unit. The ligand L coordinates to the metal ions through the nitrogen atoms of the picolylamine 
fragment, thus providing a slightly distorted $\mathrm{MN}_{2} \mathrm{O}_{4}$ octahedral environment (Figure 1, see Tables $\mathrm{S} 1-\mathrm{S} 4$ for bond lengths, bond angles and intermolecular $\mathrm{C}-\mathrm{H} \cdots \mathrm{F}$ distances).

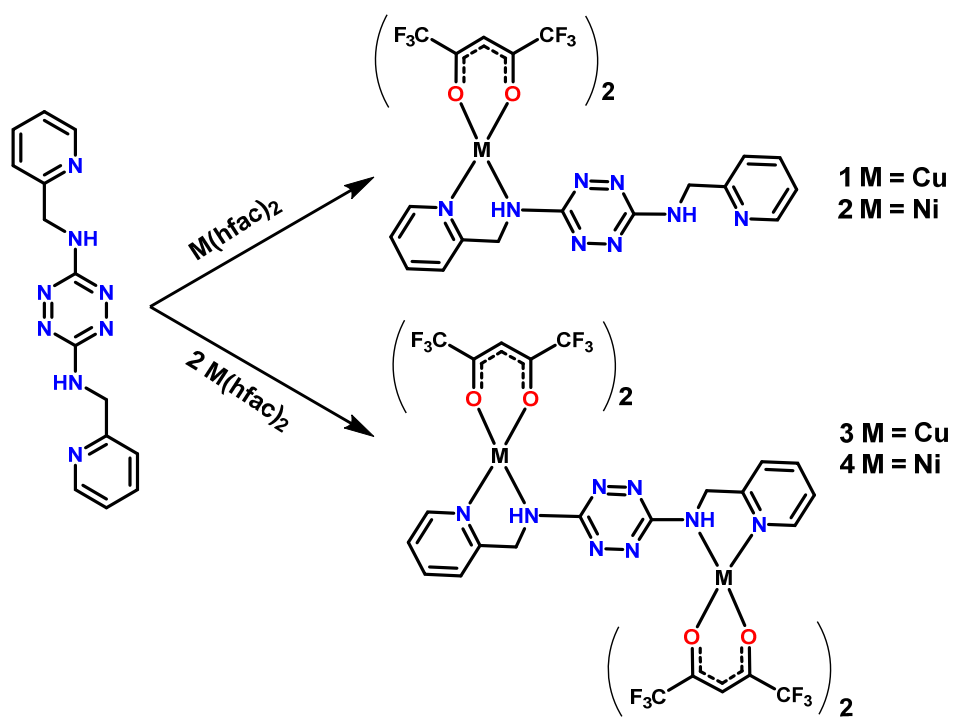

Scheme 2. Synthesis of complexes 1-4.
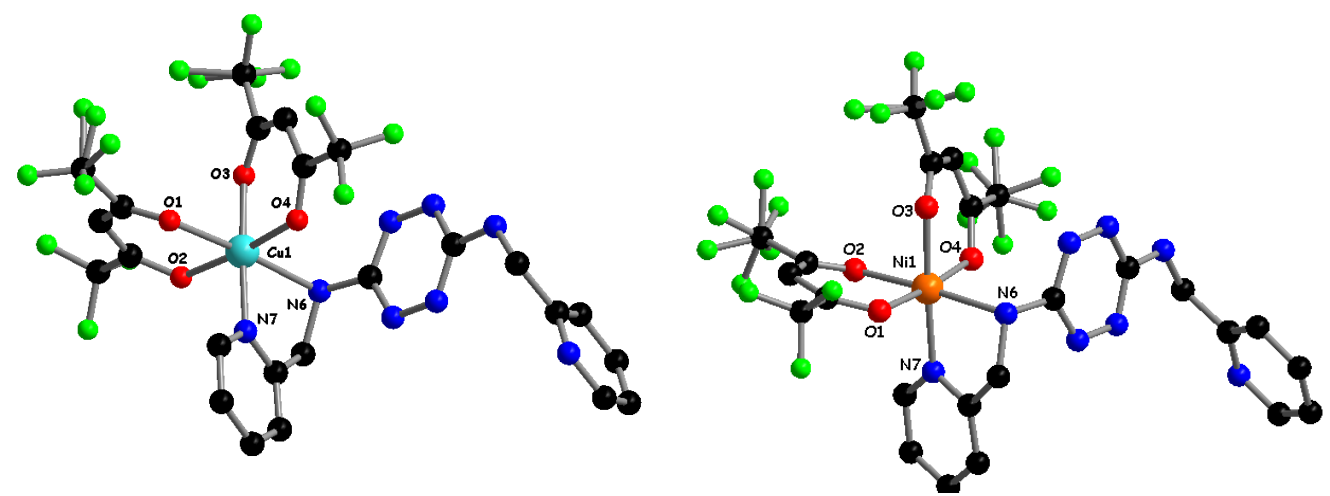

Figure 1. Crystal structures of $\mathbf{1}$ (left) and $\mathbf{2}$ (right) together with a partial atom numbering scheme. Some of the F atoms are disordered. Hydrogen atoms were omitted for clarity.

The higher distortion of the octahedron at the copper(II) ion compared to nickel(II), observed in the corresponding structures $\mathbf{1}$ and $\mathbf{2}$, is the consequence of the strong JahnTeller effect in the former. The $\mathrm{Cu}-\mathrm{O}(\mathrm{N})$ bond distances varied from 1.940(2) to 2.318(3) $\AA$, while for $\mathrm{Ni}-\mathrm{O}(\mathrm{N})$ this range was much narrower, i.e., 2.016(2)-2.170(2) $\AA$. The cis and trans $\mathrm{O}-\mathrm{Cu}-\mathrm{O}(\mathrm{N})$ bond angles spanned from $85.64(10)$ to $95.63(12)^{\circ}$ and from $173.26(10)$ to $174.72(12)^{\circ}$, respectively. The corresponding angles for 2 , that is $85.53(8)-95.00(9)^{\circ}$ and $174.78(8)-175.57(9)^{\circ}$, were similar to those in $\mathbf{1}$. In the crystal packing, short intermolecular anion $-\pi$ distances between tetrazine units and fluorine/oxygen atoms of the hfac ligands were observed (Figure 2).

Moreover, weak intermolecular $\mathrm{C}-\mathrm{H} \cdots \mathrm{F}$ type interactions occurred between fluorine atoms and $\mathrm{CH}_{2}$ and Py protons (Figures $\mathrm{S} 1$ and S2, Tables S2 and S4). The closest metal $\cdots$ metal distances in the crystal packing amounted to 8.39 (1) and $8.55 \AA$ (2).

Although compounds 3 and 4 are not isostructural, they both crystallized in the triclinic system, space group $P-1$, with half a molecule of complex in the asymmetric unit, since the TTZ bridge was located on an inversion center (Figure 3, Tables S5 and S6). 

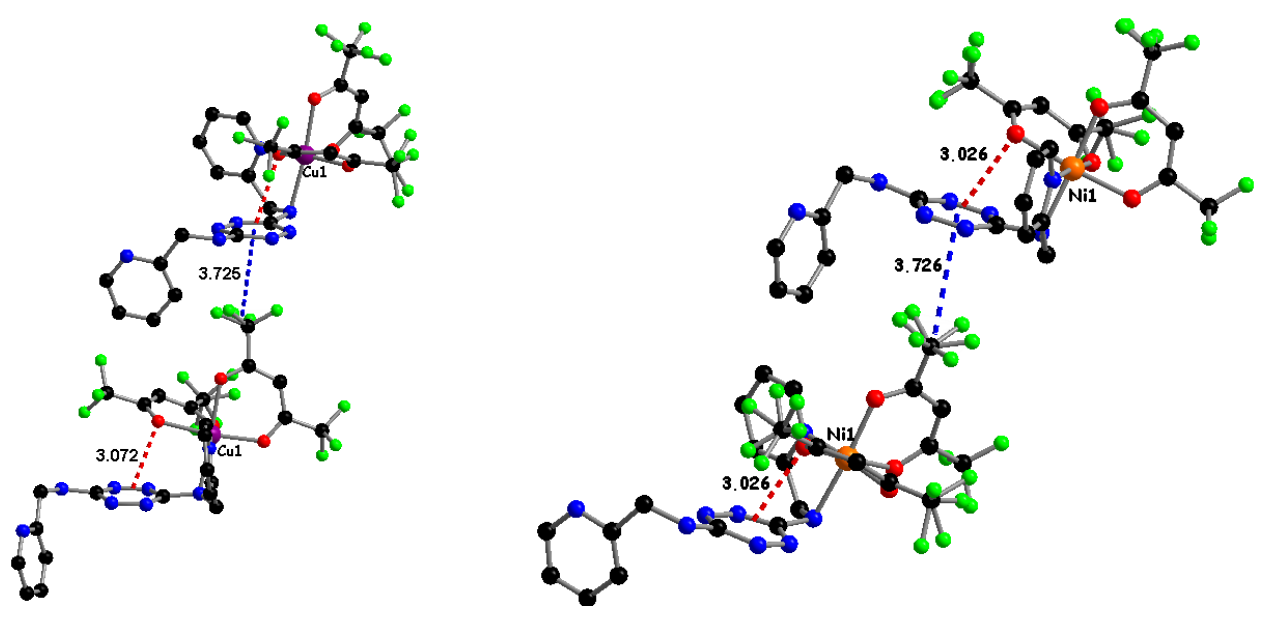

Figure 2. Anion $-\pi$ interactions between TTZ and fluorine atoms (blue lines), and TTZ and oxygen atoms (red line) in $\mathbf{1}$ (left) and 2 (right). Hydrogen atoms were omitted for clarity.
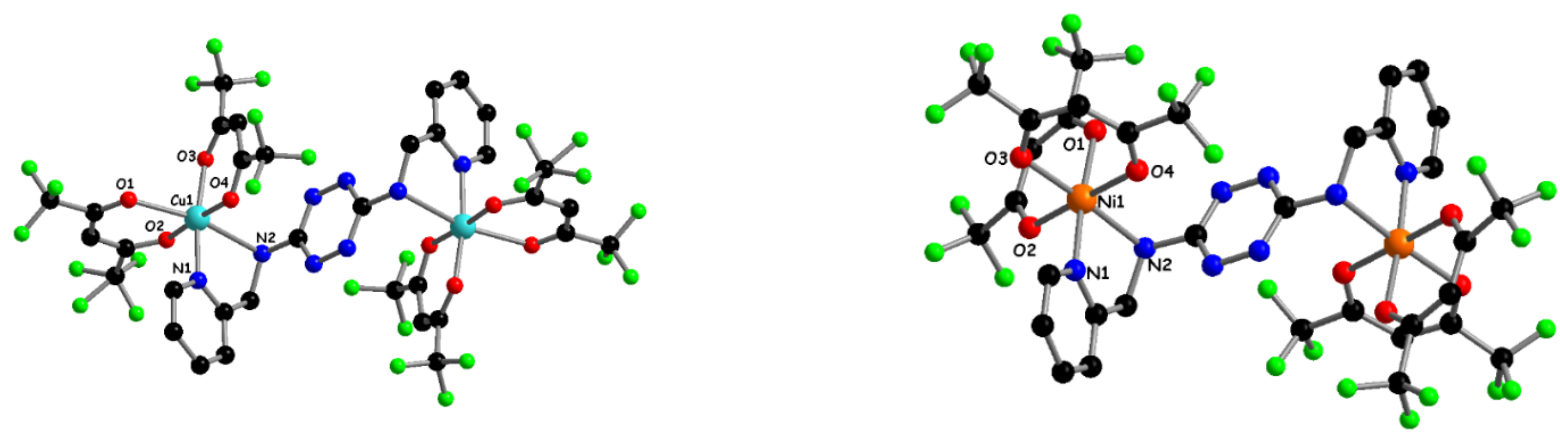

Figure 3. Crystal structures of 3 (left) and 4 (right) together with a partial atom numbering scheme. Hydrogen atoms and solvent molecules were omitted for clarity.

Two solvent molecules of crystallization per molecule of complex were present in both crystal structures and therefore, the resulting formulas are $\left[\left\{\mathrm{Cu}(\mathrm{hfac})_{2}\right\}_{2}(\mu-\mathrm{L})\right] \cdot 2 \mathrm{CH}_{3} \mathrm{OH}(3)$ and $\left[\left\{\mathrm{Ni}(\mathrm{hfac})_{2}\right\}_{2}(\mu-\mathrm{L})\right] \cdot 2 \mathrm{CH}_{3} \mathrm{CN}(4)$. The coordination environment at each copper(II) ion in 3 is an elongated octahedron, due to the Jahn-Teller effect. The equatorial $\mathrm{Cu}-\mathrm{O}(\mathrm{N})$ bond lengths varied from $1.960(3)$ to 1.995 (4) $\AA$, while the axial $\mathrm{Cu}-\mathrm{O} 1$ and $\mathrm{Cu}-\mathrm{N} 2$ distances were $2.270(4)$ and $2.498(5) \AA$, respectively. The $\mathrm{O}-\mathrm{Cu}-\mathrm{O}(\mathrm{N})_{\text {cis }}$ bond angles varied from $86.95(14)$ to $92.29(14)^{\circ}$, while the $\mathrm{O}-\mathrm{Cu}-\mathrm{O}(\mathrm{N})_{\text {trans }}$ angles spanned from $165.82(14)$ to $176.42(14)^{\circ}$. Each nickel(II) ion in 4 exhibits a distorted octahedral geometry $(5+1)$ with a much narrower range of the equatorial $\mathrm{Ni}-\mathrm{O}(\mathrm{N})$ bond lengths $(2.0230(17)-2.0399(19) \AA)$. The axial Ni-N2 distance was 2.1810(18) $\AA$. The tight range of the values of the bond angles (the values of cis- and trans-angles being in the ranges 86.40(7)-97.17(7) ${ }^{\circ}$ and $175.10(7)-176.76(6)^{\circ}$, respectively) indicates the lower distortion of the coordination octahedron compared to that at each copper center in 3 . The values of the metal $\cdots$ metal separation across the extended L bridge were 7.97 (3) and $7.82 \AA$ (4). They were of the same order of magnitude

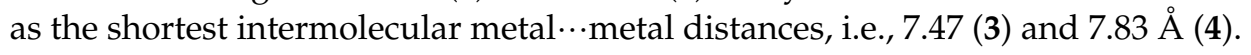

Intramolecular anion- $\pi$ interactions between the tetrazine ring and oxygen atom (3.325 ̊) (Figure S3), and intermolecular $\pi \cdots \pi$ relatively short distances between the pyridine rings ( $3.863 \AA$ ), were found in 3 (Figure 4 ), sustaining its supramolecular architecture. Similar intramolecular anion $-\pi$ interactions (3.065 $\AA$ ) existed in the structure of 4 (Figure S4). 


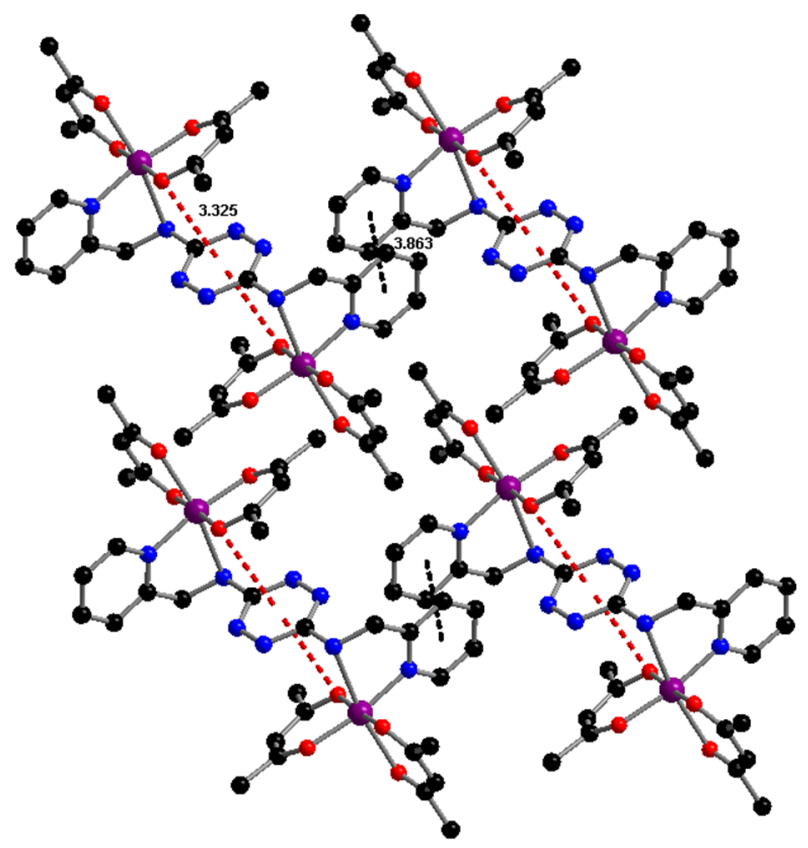

Figure 4. Intermolecular anion $-\pi$ interactions between TTZ and oxygen atoms (red line) and $\pi-\pi$ short distances between pyridyl rings (black line) in 3 . The hydrogen and fluorine atoms as well as the solvent molecules were omitted for clarity.

\subsection{Magnetic Properties of Complexes 1-4}

The magnetic properties of 1 and 2 under the form of $\chi_{M} T$ versus $T$ plots $\left[\chi_{M}\right.$ is the magnetic susceptibility per one copper(II) (1) or one nickel(II) (2) ions] are shown in Figure 5. The values of $\chi_{\mathrm{M}} T$ at room temperature were $0.41(\mathbf{1})$ and $1.21 \mathrm{~cm}^{3} \mathrm{~mol}^{-1} \mathrm{~K}$ (2). They were as expected for one magnetically non-interacting doublet $\left[\chi_{M} T=0.41 \mathrm{~cm}^{3}\right.$ $\mathrm{mol}^{-1} \mathrm{~K}$ with $S_{\mathrm{Cu}}=\frac{1}{2}$ and $\left.g_{\mathrm{Cu}}=2.10\right]$ (1) or triplet $\left[\chi_{\mathrm{M}} T=1.21 \mathrm{~cm}^{3} \mathrm{~mol}^{-1} \mathrm{~K}\right.$ with $S_{\mathrm{Ni}}=1$ and $\left.g_{\mathrm{Ni}}=2.20\right]$ (2) local spins. Upon cooling, these values remained constant until 22 (1) and $11 \mathrm{~K}(2)$ and they further decreased to $0.397(\mathbf{1})$ and $0.91 \mathrm{~cm}^{3} \mathrm{~mol}^{-1} \mathrm{~K}(2)$ at $1.9 \mathrm{~K}$. The small decrease of $\chi_{\mathrm{M}} T$ at very low temperatures for both compounds is attributed to weak intermolecular antiferromagnetic interactions (1 and $\mathbf{2}$ ) and/or zero-field splitting effects (2).

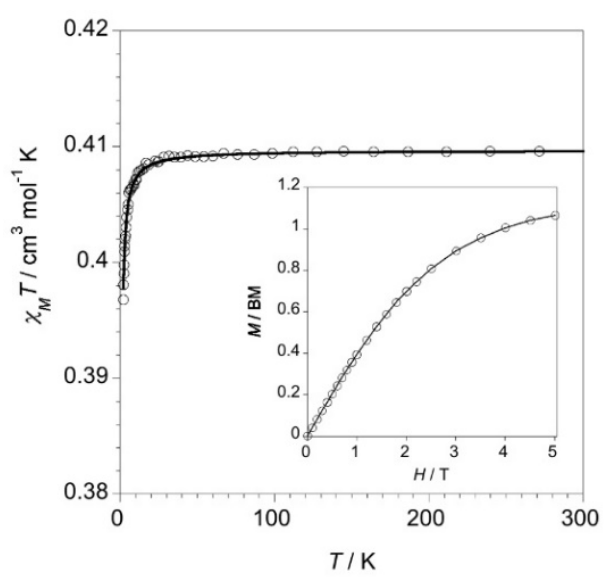

(a)

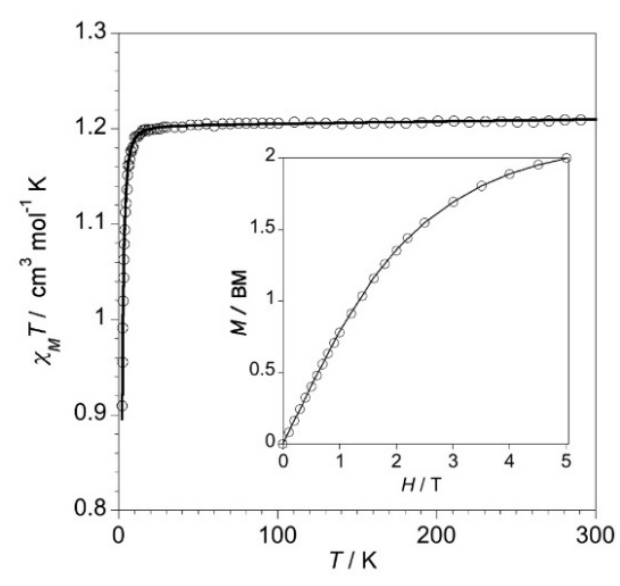

(b)

Figure 5. (a) Temperature dependence of the $\chi_{M} T$ product for 1: (o) experimental, (-) best-fit curve through Equation (1) (see text). (b) $\chi_{\mathrm{M}} T$ against $\mathrm{T}$ plot for 2: (o) experimental, (-) best-fit curve through Equations (2-4) (see text). The inset shows the magnetization versus $H$ plot for 2 at $2.0 \mathrm{~K}$. The solid line is a guide for the eye. 
Let us analyze first the magnetic data of $\mathbf{1}$. Having in mind its mononuclear nature and the above considerations, the magnetic data of this compound were treated through a Curie law for a copper(II) ion Equation (1)

$$
\chi_{\mathrm{M}}=N \beta^{2} g^{2} S(S+1) / 3 k(T-\theta)
$$

where $N, \beta$, and $k$ have their usual meanings, $S=\frac{1}{2}$ and $\theta$ is a Curie-Weiss term that was introduced to take into account the intermolecular magnetic interactions. The least-squares best-fit parameters are $g=2.09(1)$ and $\theta=-0.06(1) \mathrm{K}$. This very weak magnetic coupling is in line with the great value of the shortest intermolecular copper(II) $\cdots$ copper(II) separation in 1 (ca. $9.5 \AA$ ). This is also reflected by the $M$ vs. $H$ plot for $\mathbf{1}$ at $2.0 \mathrm{~K}$ (see inset of Figure $5 \mathrm{a}$ ), $M$ tending to a quasi-saturation value close to $1.05 \mu_{\mathrm{B}}$ at $5 \mathrm{~T}$ (that is, the value calculated through $M_{\text {sat }}=g_{\mathrm{Cu}} S_{\mathrm{Cu}}$ with $g_{\mathrm{Cu}}=2.09$ ).

Keeping these results for $\mathbf{1}$ in mind, and given that the shortest intermolecular nickel...nickel separation in 2 is very large (ca. $9.4 \AA$ ), it is reasonable to assume that the observed decrease of $\chi_{M} T$ for 2 at low temperatures was due to the zero-field splitting of the six-coordinate nickel(II) ion. The fact that the quasi-saturation value of $M$ at $5 \mathrm{~T}$ for 2 (ca. $2.0 \mu_{\mathrm{B}}$ ) was somewhat below the expected value of $M_{\mathrm{S}}=g_{\mathrm{Ni}} S_{\mathrm{Ni}}=2.20 \mu_{\mathrm{B}}$ with $\mathrm{S}_{\mathrm{Ni}}=1$ and $g_{\mathrm{Ni}}=2.20$ ) also supports the occurrence of a significant $\mathrm{zfs}$ (see inset of Figure $5 \mathrm{~b}$ ). Then, the magnetic susceptibility data of 2 were treated through Equations (2)-(4) [32]:

$$
\chi_{M}=\left(\chi_{M} \mid I+2 \chi_{M \perp}\right) / 3
$$

with

$$
\chi_{\mathrm{M}||}=\left(2 N \beta^{2} g^{2} \mid, / k T\right)[\exp (-D / k T) /(1+2 \exp (-D / k T]
$$

and

$$
\chi_{\mathrm{M} \perp}=\left(2 N \beta^{2} g^{2} \perp / D\right)\{[1-\exp (-D / k T)] /[1+2 \exp (-D / k T)]\}
$$

where $D$ is the zero-field splitting and all other parameters have their usual meanings. Best-fit parameters are $g_{||}=g_{\perp}=g_{\mathrm{Ni}}=2.20(1)$ and $D=4.48(2) \mathrm{cm}^{-1}$. This value of $D$ lies in the range of those reported for other six-coordinate nickel(II) complexes [33]. No ac signals were observed for 2, either under zero or non-zero applied dc fields. Alternatively, the magnetic susceptibility data of $\mathbf{2}$ data were fitted by considering that only the intermolecular antiferromagnetic interactions would be responsible for the observed downturn of $\chi_{\mathrm{M}} T$ at low temperatures. The too-large value obtained of the Weiss parameter Weiss $(\theta=-0.545(2)$ $\mathrm{K}$ with $D=0 \mathrm{~cm}^{-1}$ ), and having in mind the above magneto-structural features, this last approach has fewer arguments for its use.

The magnetic properties of 3 as $\chi_{M} T$ against $T$ plot $\left[\chi_{M}\right.$ is the magnetic susceptibility per two copper(II) ions] are shown in Figure 6 . At $300 \mathrm{~K}, \chi_{M} T$ for 3 was equal to $0.80 \mathrm{~cm}^{3} \mathrm{~mol}^{-1} \mathrm{~K}$, a value which was as expected for two magnetically isolated spin doublets (ca. $0.82 \mathrm{~cm}^{3} \mathrm{~mol}^{-1} \mathrm{~K}$ with $g_{\mathrm{Cu}}=2.10$ ). This value was kept upon cooling until $40 \mathrm{~K}$ and it further decreased to $0.77 \mathrm{~cm}^{3} \mathrm{~mol}^{-1} \mathrm{~K}$ at $1.9 \mathrm{~K}$. This small decrease in the low temperature region could be attributed to a very weak intramolecular antiferromagnetic coupling across the bis-bidentate L ligand (copper *.copper separation of $7.97 \AA$ ), although the intermolecular contribution to the exchange coupling could be also envisaged because

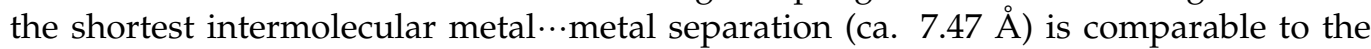
intramolecular one. 


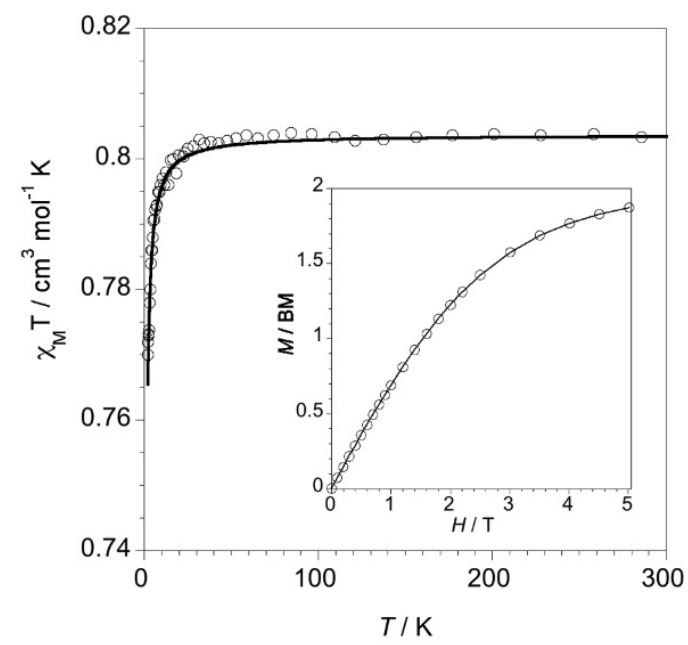

Figure 6. $\chi_{\mathrm{M}} T$ against $T$ plot for 3: (o) experimental, (-) best-fit curve through Equation (5) (see text). The inset shows the magnetization versus $H$ plot for 3 at $2.0 \mathrm{~K}$. The solid line is only an eye-guide.

The analysis of the magnetic susceptibility data of 3 through the expression for a dicopper(II) complex is shown in Equation (5)

$$
\chi_{\mathrm{M}}=\left(2 N \beta^{2} g^{2} / k T\right)[3+\exp (-J / k T)]^{-1}
$$

where $J$ is the magnetic coupling after the spin Hamiltonian $\boldsymbol{H}=-J S_{\mathrm{Cu} 1} \cdot S_{\mathrm{Cu} 2}$ and $g$ is the average Landé factor. Best-fit parameters are $J=-0.247(2) \mathrm{cm}^{-1}$ and $g=2.07(1)$. This small coupling could be considered as the upper limit because of the possibility of intermolecular magnetic interactions. The relative orientation of the magnetic orbitals in $\mathbf{3}$ allow us to account for this weak intramolecular magnetic coupling. However, the very large value of

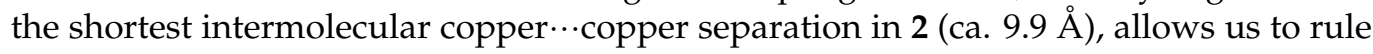
out any significant intermolecular magnetic interaction. In fact, the unpaired electron at each copper(II) ion was mainly defined by a $\left(\mathrm{dx}^{2}-\mathrm{y}^{2}\right)$-type magnetic orbital which was mainly delocalized in the equatorial plane ( $\mathrm{N} 1 \mathrm{O} 2 \mathrm{O} 3 \mathrm{O} 4$ set of atoms, the $x$ and $y$ axis being roughly defined by the equatorial bonds). These magnetic orbitals were parallel to each other in the dicopper(II) unit and they were not properly oriented to interact efficiently in the region of the bridge. The spin density on the axial $\mathrm{N} 2$ and $\mathrm{N} 2{ }^{\mathrm{i}}$ atoms [symmetry code: (i) $=1-x, 2-y, 1-z]$ was predicted to be very small, and then, the overlap between the magnetic orbitals of the copper(II) ions of 3 through the extended bis-bidentate L ligand was expected to be very poor. According to the Kahn's orbital model, the magnetic interaction in dicopper(II) complexes is proportional to the square of the overlap integral between the magnetic orbitals (the bielectronic exchange integrals being neglected) $[34,35]$. Then, a weak antiferromagnetic coupling was predicted for 3 , as observed. This is in agreement with the fact that $M$ for 3 at $2.0 \mathrm{~K}$ tends to a value somewhat below $2.0 \mu_{\mathrm{B}}$ at $5 \mathrm{~T}$ (see inset of Figure 6).

The magnetic properties of 4 in the form of both $\chi_{M} T$ and $\chi_{M}$ vs. $T$ plots $\left(\chi_{M}\right.$ is the magnetic susceptibility per two nickel(II) ions) are shown in Figure 7. At $300 \mathrm{~K}, \chi_{\mathrm{M}} T$ was equal to $2.28 \mathrm{~cm}^{3} \mathrm{~mol}^{-1} \mathrm{~K}$, a value which is as expected for a pair of non-interacting spin triplets $\left(\chi_{\mathrm{M}} T=2.28 \mathrm{~cm}^{3} \mathrm{~mol}^{-1} \mathrm{~K}\right.$ with $S_{\mathrm{Ni}}=1$ and $\left.g_{\mathrm{Ni}}=2.15\right)$. This value continuously decreased upon cooling to reach a minimum value of $0.13 \mathrm{~cm}^{3} \mathrm{~mol}^{-1} \mathrm{~K}$ at $2.0 \mathrm{~K}$. The magnetic susceptibility exhibited a maximum of $0.124 \mathrm{~cm}^{3} \mathrm{~mol}^{-1} \mathrm{~K}$ at $7.0 \mathrm{~K}$. These features are typical of an overall relatively weak antiferromagnetic behavior between the two single-ion triplet states. 


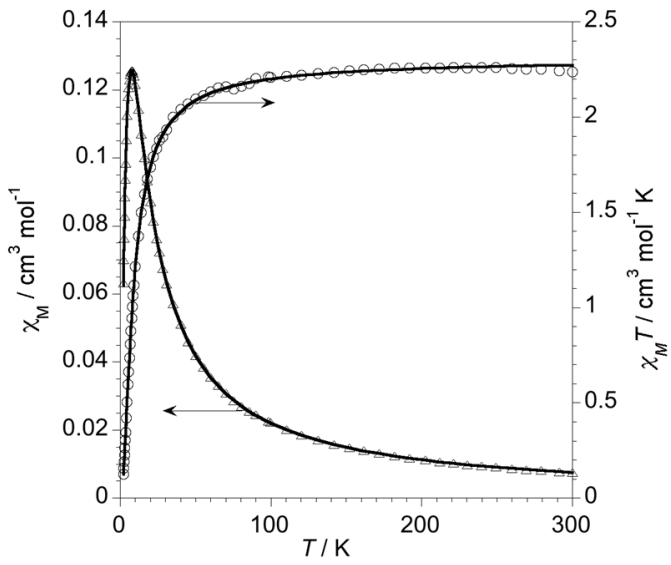

Figure 7. $\chi_{M} T(0)$ and $\chi_{M}(\Delta)$ against $T$ plots for 4 . The solid lines are the best-fit curves through Equation (6) (see text).

Given that the ground state for a six-coordinate nickel(II) ion is non-degenerate, the isotropic spin Hamiltonian $\boldsymbol{H}=-J S_{\mathrm{Ni1}} \cdot S_{\mathrm{Ni2}}$ might be appropriate to analyze the intradimer magnetic coupling $(J)$ of 4 . Nevertheless, this approach, neglecting the zfs $(D)$, works well when a relatively strong antiferromagnetic coupling occurs. In the systems where a weak antiferromagnetic coupling takes place (as in 4), or when the magnetic interaction is ferromagnetic, the effect of the $D$ parameter of the six-coordinate nickel(II) ion has to be taken into account to describe properly the magnetic behavior at low temperatures [36]. This is why the magnetic susceptibility data of $\mathbf{4}$ were analyzed by the Hamiltonian of Equation (6)

$$
\boldsymbol{H}=-J \boldsymbol{S}_{\mathrm{Ni1}} \cdot \boldsymbol{S}_{\mathrm{Ni} 2}+D\left(\boldsymbol{S}^{2}{ }_{\mathrm{z}, \mathrm{Ni} 1}+\boldsymbol{S}^{2}{ }_{\mathrm{z}, \mathrm{Ni2}}\right)+\beta H\left(g_{\mathrm{Ni1}} \boldsymbol{S}_{\mathrm{Ni1}}+g_{\mathrm{Ni} 2} \boldsymbol{S}_{\mathrm{Ni} 2}\right)
$$

where the first term accounts for the intradimer exchange coupling, the second term corresponds to the axial zfs and the third one is the Zeeman interaction with $g_{\mathrm{Ni1}}=g_{\mathrm{Ni2} 2}=$ $g_{\mathrm{Ni}}$. The best-fit parameters were $J=-4.86(2) \mathrm{cm}^{-1}, D=5.17(2) \mathrm{cm}^{-1}$ and $g_{\mathrm{Ni}}=2.15(1)$. The calculated $\chi_{M} T$ and $\chi_{M}$ curves (solid lines in Figure 7) reproduced well the magnetic data in the whole temperature range explored.

Let us to finish with a brief comment about the intramolecular antiferromagnetic coupling in 4, which was due to the spin polarization mechanism [37]. The two unpaired electrons at each six-coordinate nickel(II) ion in this complex are defined by $d\left(x^{2}-y^{2}\right)$ and $\mathrm{dz}^{2}$ type orbitals, the former one being roughly localized in the equatorial plane ( $\mathrm{N} 1 \mathrm{O} 1 \mathrm{O} 2 \mathrm{O} 4$ set of atoms), whereas the latter one lies along the O3-Ni-N2 axis. As observed for 3 , the two $d\left(x^{2}-y^{2}\right)$ magnetic orbitals were parallel to each other and their orientation towards the bridge was not appropriate to delocalize any significant spin density on the skeleton of the bridge. This was not the case for the two $\mathrm{dz}^{2}$ orbitals, the spin density on the axial $\mathrm{N} 2$ site (and symmetry-related $\mathrm{N} 2{ }^{\mathrm{i}}$ atom) being large. As the angle between the $\mathrm{Ni}-\mathrm{N} 2$ vector and the mean plane of the tetrazine ring was close to $90^{\circ}$ (ca. $109^{\circ}$ ), a significant $\pi$ overlap between the two magnetic orbitals through the -N2-(CNNC)-N2 ${ }^{\mathrm{i}}$ bridging fragment was predicted. Because of the even number of atoms in this bridging skeleton, the alternating spin densities on it led to an antiferromagnetic coupling. An odd number of atoms in the $\pi$-pathway would result in a parallel alignment of the spins of the metal ions and then in a significant ferromagnetic interaction. The efficiency of this mechanism was nicely shown by Iwamura et al., in the context of organic radicals [38], and it was successfully extended to the domain of coordination chemistry with several paramagnetic transition metal ions [39-56].

\section{Materials and Methods}

Reactions were carried out under air, and using HPLC solvents. The IR spectra were recorded on ATR Bruker Vertex 70 spectrophotometer in the $4000-400 \mathrm{~cm}^{-1}$ range. 
MALDI-TOF MS spectra were recorded on Bruker Biflex-IIITM apparatus, equipped with a 337nm $\mathrm{N}_{2}$ laser. ESI-MS spectra were achieved on a Bruker MicrO-Tof-Q 2 spectrometer. Elemental analyses were recorded using a Flash 2000 Fisher Scientific Thermo Electron analyzer. Copper(II) and nickel(II) hexafluoroacetylacetonate hydrates were purchased from Sigma Aldrich and dehydrated under high vacuum prior to their use. The L ligand was prepared as previously described [31].

$\left[\mathrm{Cu}(\mathrm{hfac})_{2}(\mathrm{~L})\right]$ 1: To a solution of $\mathbf{L}\left(0.02 \mathrm{~g}, 6.8 \times 10^{-5} \mathrm{~mol}\right)$ in $10 \mathrm{~mL}$ of dichloromethane was added a solution of bis(hexafluoroacetylacetonato)copper(II)[Cu(hfac) $\left.)_{2}\right](32.5 \mathrm{mg}$, $6.8 \times 10^{-5} \mathrm{~mol}$ ) in $10 \mathrm{~mL}$ of methanol. The mixture was stirred at room temperature for $1 \mathrm{~h}$. The color changed from red to brown during the reaction. The resulting solution was left undisturbed for two days at room temperature. During this period, yellow-brown crystals $(0.025 \mathrm{~g}, 47 \%)$, suitable for single-crystal X-ray analysis, were obtained. MALDI-TOF MS: $m / z=563.9[\mathrm{Cu}(\mathrm{hfac})(\mathrm{L})]^{+}$. ESI-MS: $\mathrm{m} / z=563.9[\mathrm{Cu}(\mathrm{hfac})(\mathrm{L})]^{+}$. IR $\left(\right.$ATR, $\left.\mathrm{cm}^{-1}\right): 3415(\mathrm{w})$, $1643(\mathrm{~s}), 1551(\mathrm{~m}), 1252(\mathrm{~s}), 1199(\mathrm{~s}), 1135(\mathrm{~s}), 928(\mathrm{w}), 793(\mathrm{~s}), 669$ (s), $583(\mathrm{~s}), 516(\mathrm{~m})$ Elemental analysis calcd for $\mathrm{C}_{24} \mathrm{H}_{16} \mathrm{~F}_{12} \mathrm{~N}_{8} \mathrm{O}_{4} \mathrm{Cu}: \mathrm{C}, 37.34 ; \mathrm{H}, 2.09 ; \mathrm{N}, 14.54 \%$. Found: $\mathrm{C}$, $37.55 ; \mathrm{H}, 2.36$; N $14.78 \%$.

$\left[\mathrm{Ni}(\mathrm{hfac})_{2}(\mathrm{~L})\right] 2$ : To a solution of $\mathrm{L}\left(0.02 \mathrm{~g}, 6.8 \times 10^{-5} \mathrm{~mol}\right)$ in $10 \mathrm{~mL}$ of dichloromethane was added a solution of [ $\left.\mathrm{Ni}(\mathrm{hfac})_{2}\right]\left(32.1 \mathrm{mg}, 6.8 \times 10^{-5} \mathrm{~mol}\right)$ in $10 \mathrm{~mL}$ of acetonitrile. The mixture was stirred at room temperature for one hour. As in 1, the color of the solution changed from red to brown, evidencing the complex formation. The resulting solution was left undisturbed for one day at room temperature, yielding brown crystals $(0.037 \mathrm{~g}$, $70 \%$ ) suitable for single-crystal X-ray analysis. ESI-MS: $m / z=766\left[\mathrm{Ni}(\mathrm{hfac})_{2}(\mathrm{~L})\right]^{+}$. IR (ATR, $\mathrm{cm}^{-1}$ ): 3219 (w), 1642 (s), 1482 (s), 1253 (s), 1189 (s), 1139 (s), 945 (w), 792 (s), 671 (s), 585 (s), $529(\mathrm{~m})$. Elemental analysis calcd for $\mathrm{C}_{24} \mathrm{H}_{16} \mathrm{~F}_{12} \mathrm{~N}_{8} \mathrm{O}_{4} \mathrm{Ni}$ : C, 37.57; $\mathrm{H}, 2.10 ; \mathrm{N}, 14.60 \%$. Found: $\mathrm{C}, 37.65 ; \mathrm{H}, 2.44 ; \mathrm{N}, 14.85 \%$.

$\left[\left\{\mathrm{Cu}(\mathrm{hfac})_{2}\right\}_{2}(\pi-\mathrm{L})\right] \cdot 2 \mathrm{CH}_{3} \mathrm{OH}$ 3: To a solution of $\mathrm{L}\left(0.02 \mathrm{~g}, 6.8 \times 10^{-5} \mathrm{~mol}\right)$ in $10 \mathrm{~mL}$ of dichloromethane was added a solution of $\left[\mathrm{Cu}(\mathrm{hfac})_{2}\right]\left(130 \mathrm{mg}, 27.2 \times 10^{-5} \mathrm{~mol}\right)$ in $20 \mathrm{~mL}$ of methanol. The mixture was stirred at $70^{\circ} \mathrm{C}$ for one hour. During the reaction, the color changed from red to brown. The resulting solution was left undisturbed for one day at room temperature, yielding yellow-brown crystals $(0.051 \mathrm{~g}, 57 \%)$ suitable for single-crystal X-ray analysis. MALDI-TOF MS: $m / z=1246\left[\left\{\mathrm{Cu}(\mathrm{hfac})_{2}\right\}_{2}(\mathrm{~L})\right]^{+}$. IR $\left(\right.$ATR, $\left.\mathrm{cm}^{-1}\right): 3415$ (w), $1642(\mathrm{~s}), 1552(\mathrm{~m}), 1253(\mathrm{~s}), 1199(\mathrm{~s}), 1201$ (s), $928(\mathrm{w}), 794(\mathrm{~s}), 670(\mathrm{~s}), 584(\mathrm{~s}), 517(\mathrm{~m})$. Elemental analysis calcd for $\mathrm{C}_{36} \mathrm{H}_{26} \mathrm{~F}_{24} \mathrm{~N}_{8} \mathrm{O}_{10} \mathrm{Cu}_{2}$ : C, 32.91; $\mathrm{H}, 1.99 ; \mathrm{N}, 8.52 \%$. Found: $\mathrm{C}$, 33.30; $\mathrm{H}, 2.12 ; \mathrm{N}, 8.67 \%$.

[ $\left.\left\{\mathrm{Ni}(\mathrm{hfac})_{2}\right\}_{2}(\pi-\mathrm{L})\right] \cdot 2 \mathrm{CH}_{3} \mathrm{CN}$ 4: To a solution of $\mathrm{L}\left(0.02 \mathrm{~g}, 6.8 \times 10^{-5} \mathrm{~mol}\right)$ in $10 \mathrm{~mL}$ of dichloromethane was added a solution of [Ni(hfac) $\left.)_{2}\right]\left(96.5 \mathrm{mg}, 20.4 \times 10^{-5} \mathrm{~mol}\right)$ in $20 \mathrm{~mL}$ of acetonitrile. The mixture was stirred at $70^{\circ} \mathrm{C}$ for one hour. During the reaction, the color changed from red to red-brown. The resulting solution was left undisturbed for one day at room temperature. Yellow-brown crystals $(0.06 \mathrm{~g}, 67 \%)$ suitable for single-crystal X-ray analysis were collected after this period. MALDI-TOF MS: $m / z=1238\left[\left\{\mathrm{Ni}(\mathrm{hfac})_{2}\right\}_{2}(\mathrm{~L})\right]^{+}$. IR (ATR, cm ${ }^{-1}$ ): 3418 (w), 1646 (s), 1548 (m), 1249 (s), 1203 (s), 1195 (s), 932 (w), 798 (s), 667 (s), 579 (s), 509 (m). Elemental analysis calcd for $\mathrm{C}_{38} \mathrm{H}_{24} \mathrm{~F}_{24} \mathrm{~N}_{10} \mathrm{O}_{8} \mathrm{Ni}_{2}$ : C, 34.52; $\mathrm{H}, 1.83 ; \mathrm{N}$, $8.88 \%$. Found: C, $34.89 ; \mathrm{H}, 1.95 ; \mathrm{N} 9.22 \%$.

Variable temperature direct current (dc) magnetic susceptibility measurements (1.9-300 K) under applied dc magnetic fields of $5000 \mathrm{G}(T \geq 50 \mathrm{~K})$ and $100 \mathrm{G}(1.9 \leq T<50 \mathrm{~K})$ and variable-field (0-5 T) magnetization measurements $(2.0 \mathrm{~K})$ on crushed crystals of 1-4 were carried out with a Quantum Design SQUID magnetometer. Alternating current (ac) magnetic susceptibility measurements at low temperatures (2.0-8.0 K) under different applied dc magnetic fields in the range $0-2500 \mathrm{G}$ were performed for 2 by using a Quantum Design Physical Property Measurement System (PPMS). The magnetic susceptibility data of these compounds were corrected for the diamagnetism of the constituent atoms and the sample holder (a plastic bag).

X-ray single crystal diffraction data were collected on an Agilent Technologies SuperNova diffractometer equipped with AtlasCCD detector and micro-focus $\mathrm{Cu}-\mathrm{K} \alpha$ radiation 
$\left(\lambda=1.54184 \AA\right.$ ). The structures were solved by direct methods and refined on $\mathrm{F}^{2}$ by full matrix least-squares techniques using the SHELX97 (G.M. Sheldrick, 1998) package. All non-H atoms were refined anisotropically and multiscan empirical absorption was applied using the CrysAlisPro program (CrysAlisPro, AgilentTechnologies, V1.171.38.41r, 2015). The hydrogen atoms were included in the calculation without refinement. A summary of the crystallographic data and the structure refinement for single crystals of compounds 1-4 is given in Table 1 .

Table 1. Crystallographic data, details of data collection and structure refinement parameters for compounds 1-4.

\begin{tabular}{|c|c|c|c|c|}
\hline & 1 & 2 & 3 & 4 \\
\hline Formula & $\mathrm{C}_{24} \mathrm{H}_{16} \mathrm{~F}_{12} \mathrm{~N}_{8} \mathrm{O}_{4} \mathrm{Cu}$ & $\mathrm{C}_{24} \mathrm{H}_{16} \mathrm{~F}_{12} \mathrm{~N}_{8} \mathrm{O}_{4} \mathrm{Ni}$ & $\mathrm{C}_{36} \mathrm{H}_{26} \mathrm{~F}_{24} \mathrm{~N}_{8} \mathrm{O}_{10} \mathrm{Cu}_{2}$ & $\mathrm{C}_{38} \mathrm{H}_{24} \mathrm{~F}_{24} \mathrm{~N}_{10} \mathrm{O}_{8} \mathrm{Ni}_{2}$ \\
\hline$M\left[\mathrm{~g} \cdot \mathrm{mol}^{-1}\right]$ & 771.99 & 767.16 & 1313.75 & 1322.05 \\
\hline$T[\mathrm{~K}]$ & $89.9(3)$ & $150.00(10)$ & $150.00(10)$ & $149.56(10)$ \\
\hline Crystal system & monoclinic & monoclinic & triclinic & triclinic \\
\hline Space group & $P 2_{1} / n$ & $P 2_{1} / n$ & $P-1$ & $P-1$ \\
\hline$a[\AA]$ & $9.479(3)$ & $9.4370(10)$ & $9.901(7)$ & $9.2160(2)$ \\
\hline$b[\AA]$ & $14.191(5)$ & $14.299(2)$ & $11.416(7)$ & $10.5636(3)$ \\
\hline$c[\AA]$ & $22.002(6)$ & $22.162(4)$ & $11.823(3)$ & 13.4199(3) \\
\hline$\alpha\left[^{\circ}\right]$ & 90 & 90 & $91.277(4)$ & $89.369(2)$ \\
\hline$\beta\left[^{\circ}\right]$ & $98.581(2)$ & $99.569(15)$ & $96.619(5)$ & $77.005(2)$ \\
\hline$\gamma\left[^{\circ}\right]$ & 90 & 90 & $100.342(5)$ & $73.297(2)$ \\
\hline$V\left[\AA^{3}\right]$ & 2926.5(16) & $2948.9(7)$ & 1304.6(13) & 1217.30(5) \\
\hline$Z$ & 4 & 4 & 1 & 1 \\
\hline$\rho_{\text {calcd }}\left[\mathrm{g} \mathrm{cm}^{-3}\right]$ & 1.752 & 1.728 & 1.672 & 1.803 \\
\hline$\mu\left[\mathrm{mm}^{-1}\right]$ & 2.216 & 2.103 & 2.343 & 2.388 \\
\hline Goodness-of-fit on $F^{2}$ & 1.027 & 1.041 & 1.080 & 1.055 \\
\hline Final $R_{1} \mathrm{a} / \mathrm{w} R_{2}{ }^{\mathrm{b}}[I>2 \sigma(I)]$ & $0.0632 / 0.1576$ & $0.0555 / 0.1457$ & $0.0881 / 0.2453$ & $0.0573 / 0.1524$ \\
\hline$R_{1}^{\mathrm{a}} / \mathrm{w} R_{2}^{\mathrm{b}}$ (all data) & $0.0698 / 0.1635$ & $0.0600 / 0.1498$ & $0.0931 / 0.2525$ & $0.0625 / 0.1589$ \\
\hline
\end{tabular}

${ }^{\mathrm{a}} \mathrm{R}_{1}=\sum|| \mathrm{F}_{\mathrm{o}}|-| \mathrm{F}_{\mathrm{c}}|| / \sum\left|\mathrm{F}_{\mathrm{o}}\right| .{ }^{\mathrm{b}} \mathrm{wR}_{2}=\left[\sum \mathrm{w}\left(\mathrm{F}_{\mathrm{o}}{ }^{2}-\mathrm{F}_{\mathrm{c}}{ }^{2}\right)^{2} / \sum \mathrm{w}\left(\mathrm{F}_{\mathrm{o}}{ }^{2}\right)^{2}\right]^{1 / 2} ; \mathrm{w}=1 /\left[\sigma^{2}\left(\mathrm{~F}_{0}{ }^{2}\right)+(\mathrm{aP})^{2}+\mathrm{bP}\right]$ where $\mathrm{P}=\left[\max \left(\mathrm{F}_{0}{ }^{2}, 0\right)+2 \mathrm{~F}_{\mathrm{c}}{ }^{2}\right] / 3$.

Crystallographic data for the four structures have been deposited with the Cambridge Crystallographic Data Centre, deposition numbers CCDC 2070.862 (1), CCDC 2070.863 (2), CCDC 2070.864 (3), CCDC 2070.865 (4). These data can be obtained free of charge from CCDC, 12 Union road, Cambridge CB2 1EZ, UK (e-mail: deposit@ccdc.cam.ac.uk or http://www.ccdc.cam.ac.uk).

\section{Conclusions}

The versatility of 3,6-bis(picolylamino)-1,2,4,5-tetrazine (L) as a potentially monotopic and ditopic ligand has been exploited in this work through the preparation of mono- and binuclear copper(II) and nickel(II) complexes where the picolylamine fragments coordinate the metal centers in bidentate fashion. Their coordination sphere is completed by two hfac ligands, thus providing distorted octahedral $\mathrm{MN}_{2} \mathrm{O}_{4}$ coordination geometries in complexes 1-4. The supramolecular solid state architecture of the complexes is sustained by intramolecular and intermolecular anion $-\pi$ interactions between the tetrazine ring and oxygen and fluorine atoms, together with intermolecular $\pi-\pi$ stacking. The magnetic properties of the four complexes have been investigated through static (dc) magnetic susceptibility measurements. Interestingly, the weak intramolecular antiferromagnetic interactions occurring in the binuclear $\mathrm{Ni}$ (II) complex 4 can be explained thanks to a 
spin polarization mechanism mediated by the tetrazine bridge. The involvement of the tetrazine (TTZ) ring in the magnetic coupling pathway is very interesting in view of the possibility to access the radical anion species of TTZ, which should strongly enhance the coupling between the two metal centers [17]. Besides, the selective preparation of monoand binuclear species opens the way towards the controlled synthesis of heterobimetallic complexes.

Supplementary Materials: The following are available online, Figure S1: Intermolecular $\mathrm{C}-\mathrm{H} \cdot \mathrm{F}$ hydrogen bonds in 1, Figure S2: Intermolecular C-H F hydrogen bonds in 2, Figure S3: Intermolecular anion- $\pi$ interactions between TTZ and oxygen atoms (red line) in 3. Hydrogen atoms and solvent molecules were omitted for clarity. Figure S4: Intermolecular anion- $\pi$ interactions between TTZ and oxygen atoms (red line) in 4 . Hydrogen atoms and solvent molecules were omitted for clarity, Table S1: Bond lengths $(\AA)$ and bond angles $\left(^{\circ}\right)$ for 1, Table S2: Hydrogen bonds parameters for 1, Table S3: Bond lengths $(\AA)$ and bond angles $\left(^{\circ}\right)$ for 2, Table S4: Hydrogen bonds parameters for 2, Table S5: Bond lengths $(\AA)$ and bond angles $\left(^{\circ}\right)$ for 3, Table S6: Bond lengths $(\AA)$ and bond angles $\left(^{\circ}\right)$ for 4.

Author Contributions: N.A. conceived the project; N.A., O.S. and A.E.-G. designed and discussed the experiments; O.S. synthesized and characterized the ligands and the complexes; F.L. and M.J. carried out the magnetic study; N.A. and M.J. wrote and/or reviewed the manuscript with contributions from all the authors. All authors have read and agreed to the published version of the manuscript.

Funding: Financial support in France from the CNRS and University of Angers and in Spain from the Ministerio Español de Ciencia, Innovación y Universidades (Project PID2019-109735GB-I00) and the Generalitat Valenciana (Project AICO/2020/183) is gratefully acknowledged. One of us (O.S.) thanks the French Embassy in Kiev for a grant.

Institutional Review Board Statement: Not applicable.

Informed Consent Statement: Not applicable.

Data Availability Statement: Not applicable.

Acknowledgments: Ingrid Freuze (Plateau ASTRAL, SFR Matrix, University of Angers) is gratefully acknowledged for MS characterization of the complexes.

Conflicts of Interest: The authors declare no conflict of interest. The funders had no role in the design of the study; in the collection, analyses, or interpretation of data; in the writing of the manuscript, or in the decision to publish the results.

Sample Availability: Samples of the compounds are not available from the authors.

\section{References}

1. Saracoglu, N. Recent advances and applications in 1,2,4,5-tetrazine chemistry. Tetrahedron 2007, 63, 4199-4236. [CrossRef]

2. Clavier, G.; Audebert, P. s-Tetrazines as Building Blocks for New Functional Molecules and Molecular Materials. Chem. Rev. 2010, 110, 3299-3314. [PubMed]

3. Audebert, P.; Miomandre, F.; Clavier, G.; Vernières, M.-C.; Badré, S.; Méallet-Renault, R. Synthesis and Properties of New Tetrazines Substituted by Heteroatoms: Towards the World's Smallest Organic Fluorophores. Chem. Eur. J. 2005, 11, 5667-5673. [CrossRef]

4. Gong, Y.-H.; Miomandre, F.; Méallet-Renault, R.; Badré, S.; Galmiche, L.; Tang, J.; Audebert, P.; Clavier, G. Synthesis and Physical Chemistry of s-Tetrazines: Which Ones are Fluorescent and Why? Eur. J. Org. Chem. 2009, 6121-6128. [CrossRef]

5. Quinton, C.; Alain-Rizzo, V.; Dumas-Verdes, C.; Clavier, G.; Miomandre, F.; Audebert, P. Design of New Tetrazine-Triphenylamine Bichromophores-Fluorescent Switching by Chemical Oxidation. Eur. J. Org. Chem. 2012, 2012, 1394-1403.

6. Quinton, C.; Alain-Rizzo, V.; Dumas-Verdes, C.; Miomandre, F.; Audebert, P. Tetrazine-triphenylamine dyads: Influence of the nature of the linker on their properties. Electrochim. Acta 2013, 110, 693-701. [CrossRef]

7. Jordan, B.J.; Pollier, M.A.; Miller, L.A.; Tiernan, C.; Clavier, G.; Audebert, P.; Rotello, V.M. Redox-Modulated Recognition of Tetrazines Using Thioureas. Org. Lett. 2007, 9, 2835-2838.

8. Zhou, Q.; Audebert, P.; Clavier, G.; Méallet-Renault, R.; Miomandre, F.; Shaukat, Z.; Vu, T.-T.; Tang, J. New Tetrazines Functionalized with Electrochemically and Optically Active Groups: Electrochemical and Photoluminescence Properties. J. Phys. Chem. C 2011, 115, 21899-21906. [CrossRef]

9. Kurach, E.; Djurado, D.; Rimarčik, J.; Kornet, A.; Wlostowski, M.; Lukeš, V.; Pécaut, J.; Zagorska, M.; Pron, A. Effect of substituents on redox, spectroscopic and structural properties of conjugated diaryltetrazines-A combined experimental and theoretical study. Phys. Chem. Chem. Phys. 2011, 13, 2690-2700. 
10. Schottel, B.L.; Chifotides, H.T.; Dunbar, K.R. Anion- $\pi$ interactions. Chem. Soc. Rev. 2008, 37, 68-83. [CrossRef]

11. Frontera, A.; Gamez, P.; Mascal, M.; Mooibroek, T.J.; Reedijk, J. Putting Anion- $\pi$ Interactions into Perspective. Angezw. Chem. Int. Ed. 2011, 50, 9564-9583. [CrossRef]

12. Savastano, M.; Bazzicalupi, C.; Giorgi, C.; García-Gallarín, C.; López de la Torre, M.D.; Pichierri, F.; Bianchi, A.; Melguizo, M. Anion Complexes with Tetrazine-Based Ligands: Formation of Strong Anion $-\pi$ Interactions in Solution and in the Solid State. Inorg. Chem. 2016, 55, 8013-8024. [CrossRef]

13. Savastano, M.; García-Gallarín, C.; López de la Torre, M.D.; Bazzicalupi, C.; Bianchi, A.; Melguizo, M. Anion- $\pi$ and lone pair- $\pi$ interactions with s-tetrazine-based ligands. Coord. Chem. Rev. 2019, 397, 112-137. [CrossRef]

14. Savastano, M.; García-Gallarín, C.; Giorgi, C.; Gratteri, P.; López de la Torre, M.D.; Bazzicalupi, C.; Bianchi, A.; Melguizo, M. Solid State and Solution Study on the Formation of Inorganic Anion Complexes with a Series of Tetrazine-Based Ligands. Molecules 2019, 24, 2247. [CrossRef]

15. Kaim, W. The coordination chemistry of 1,2,4,5-tetrazines. Coord. Chem. Rev. 2002, 230, 127-139. [CrossRef]

16. Stetsiuk, O.; Abhervé, A.; Avarvari, N. 1,2,4,5-Tetrazine based ligands and complexes. Dalton Trans. 2020, 49, 5759-5777. [CrossRef] [PubMed]

17. Mavragani, N.; Kitos, A.A.; Brusso, J.L.; Murugesu, M. Enhancing Magnetic Communication between Metal Centres: The Role of s-Tetrazine Based Radicals as Ligands. Chem. Eur. J. 2021, 27, 5091-5106. [CrossRef] [PubMed]

18. Schottel, B.L.; Chifotides, H.T.; Shatruk, M.; Chouai, A.; Pérez, L.M.; Bacsa, J.; Dunbar, K.R. Anion $-\pi$ Interactions as Controlling Elements in Self-Assembly Reactions of Ag(I) Complexes with $\pi$-Acidic Aromatic Rings. J. Am. Chem. Soc. 2006, 128, 5895-5912. [CrossRef] [PubMed]

19. Alexandropoulos, D.I.; Dolinar, B.S.; Vignesh, K.R.; Dunbar, K.R. Putting a New Spin on Supramolecular Metallacycles: Co 3 Triangle and $\mathrm{Co}_{4}$ Square Bearing Tetrazine-Based Radicals as Bridges. J. Am. Chem. Soc. 2017, 139, 11040-11043. [CrossRef]

20. Giles, I.D.; Chifotides, H.T.; Shatruck, M.; Dunbar, K.R. Anion-templated self-assembly of highly stable Fe(II) pentagonal metallacycles with short anion- $\pi$ contacts. Chem. Commun. 2011, 47, 12604-12606. [CrossRef] [PubMed]

21. Glöckle, M.; Hubler, K.; Kümmerer, H.-J.; Denninger, G.; Kaim, W. Dicopper(I) Complexes with Reduced States of 3,6-Bis(2‘pyrimidyl)-1,2,4,5-tetrazine: Crystal Structures and Spectroscopic Properties of the Free Ligand, a Radical Species, and a Complex of the 1,4-Dihydro Form. Inorg. Chem. 2001, 40, 2263-2269. [CrossRef]

22. Woods, T.J.; Ballesteros-Rivas, M.F.; Ostrovsky, S.M.; Palii, A.V.; Reu, O.S.; Klokishiner, S.I.; Dunbar, K.R. Strong Direct Magnetic Coupling in a Dinuclear Co ${ }^{\mathrm{II}}$ Tetrazine Radical Single-Molecule Magnet. Chem. Eur. J. 2015, 21, 10302-10305. [CrossRef]

23. Woods, T.J.; Stout, H.D.; Dolinar, B.S.; Vignesh, K.R.; Ballesteros-Rivas, M.F.; Achim, C.; Dunbar, K.R. Strong Ferromagnetic Exchange Coupling Mediated by a Bridging Tetrazine Radical in a Dinuclear Nickel Complex. Inorg. Chem. 2017, 56, 12094-12097. [CrossRef]

24. Lemes, M.A.; Brunet, G.; Pialat, A.; Ungur, L.; Korobkov, I.; Murugesu, M. Strong ferromagnetic exchange coupling in a $\left\{\mathrm{Ni}^{\mathrm{II}}{ }_{4}\right\}$ cluster mediated through an air-stable tetrazine-based radical anion. Chem. Commun. 2017, 53, 8660-8663. [CrossRef] [PubMed]

25. Tripathy, S.K.; van der Meer, M.; Sahoo, A.; Laha, P.; Dehury, N.; Plebst, S.; Sarkar, B.; Samanta, K.; Patra, S. A dinuclear $\left[\left\{(p-c y m) \mathrm{Ru}^{\mathrm{II}} \mathrm{Cl}\right\}_{2}\left(\mu \text {-bpytz }{ }^{\bullet-}\right)\right]^{+}$complex bridged by a radical anion: Synthesis, spectroelectrochemical, EPR and theoretical investigation (bpytz = 3,6-bis(3,5-dimethylpyrazolyl)1,2,4,5-tetrazine; $p$-cym = p-cymene). Dalton Trans. 2016, 45, 12532-12538. [CrossRef] [PubMed]

26. Lemes, M.A.; Stein, H.N.; Gabidullin, B.; Robeyns, K.; Clérac, R.; Murugesu, M. Probing Magnetic-Exchange Coupling in Supramolecular Squares Based on Reducible Tetrazine-Derived Ligands. Chem. Eur. J. 2018, 24, 4259-4263. [CrossRef] [PubMed]

27. Nazarenko, I.; Pop, F.; Sun, Q.; Hauser, A.; Lloret, F.; Julve, M.; El-Ghayoury, A.; Avarvari, N. Structural, photophysical and magnetic properties of transition metal complexes based on the dipicolylamino-chloro-1,2,4,5-tetrazine ligand. Dalton Trans. 2015, 44, 8855-8866. [CrossRef]

28. Pop, F.; Ding, J.; Lawson Daku, L.M.; Hauser, A.; Avarvari, N. Tetrathiafulvalene-s-tetrazine: Versatile platform for donor-acceptor systems and multifunctional ligands. RSC Adv. 2013, 3, 3218-3221. [CrossRef]

29. Stetsiuk, O.; El-Ghayoury, A.; Hauser, A.; Avarvari, N. Dipicolylamino-methoxy-1,2,4,5-tetrazine ligand and its metal complexes: Structural and photophysical studies. Polyhedron 2019, 170, 232-238. [CrossRef]

30. Stetsiuk, O.; Petrusenko, S.R.; Sorace, L.; Lupan, A.; Attia, A.A.A.; Kokozay, V.N.; El-Ghayoury, A.; Avarvari, N. Versatile coordination behaviour of the chloro-tetrazine-picolylamine ligand: Mixed-valence binuclear $\mathrm{Cu}(\mathrm{I}) / \mathrm{Cu}(\mathrm{II})$ complexes. Dalton Trans 2019, 48, 11966-11977. [CrossRef]

31. Stetsiuk, O.; El-Ghayoury, A.; Lloret, F.; Julve, M.; Avarvari, N. Mononuclear and One-Dimensional Cobalt(II) Complexes with the 3,6-Bis(picolylamino)-1,2,4,5-tetrazine Ligand. Eur. J. Inorg. Chem. 2018, 449-457. [CrossRef]

32. Kahn, O. Molecular Magnetism; VCH: Weinheim, Germany, 1993; p. 18.

33. Boça, R. Zero-field splitting in metal complexes. Coord. Chem. Rev. 2004, 248, 757-815. [CrossRef]

34. Girerd, J.J.; Charlot, M.F.; Kahn, O. Orbital interaction in one-dimensional magnetic compounds. Mol. Phys. 1977, 34, 1063-1076. [CrossRef]

35. Kahn, O.; Charlot, M.F. Overlap density in binuclear complexes: A topological approach of the exchange interaction. Nouv. J. Chim. 1980, 4, 567-576. 
36. De Munno, G.; Julve, M.; Lloret, F.; Derory, A. 2,2'-Bipyrimidine (bpym)-bridged Dinuclear Complexes-Part 1. Preparation, Crystal Structure, and Magnetic Properties of $\left[\mathrm{Ni}_{2}\left(\mathrm{H}_{2} \mathrm{O}\right)_{8}(\mathrm{bpym})\right]\left(\mathrm{NO}_{3}\right)_{4}$ and $\left[\mathrm{Ni}_{2}\left(\mathrm{H}_{2} \mathrm{O}\right)_{8}(\mathrm{bpym})\right]\left(\mathrm{SO}_{4}\right)_{2} \cdot 2 \mathrm{H}_{2} \mathrm{O}$. J. Chem. Soc. Dalton Trans. 1993, 1179-1184. [CrossRef]

37. McConnell, H.M. Ferromagnetism in Solid Free Radicals. J. Chem. Phys. 1963, 39, 1910. [CrossRef]

38. Izuoka, A.; Murata, S.; Sugawara, T.; Iwamura, H. Molecular Design and Model Experiments of Ferromagnetic Intermolecular Interaction in the Assembly of High-spin Organic Molecules. Generation and Characterization of the Spin States of Isomeric Bis(phenylmethylenyl)[2.2]paracyclophanes. J. Am. Chem. Soc. 1987, 109, 2631-2639. [CrossRef]

39. Oshio, H. Control of the Intermolecular Magnetic interaction by the Spin Polarization of d $\pi$-Electrons: Ferromagnetic Interaction between Iron Centres through an Organic Bridging Ligand. J. Chem. Soc. Chem. Commun. 1991, 240-241. [CrossRef]

40. Kollmar, C.; Couty, M.; Kahn, O. A Mechanism for the Ferromagnetic Coupling in Decamethylferrocenium Tetracyanoethenide. J. Am. Chem. Soc. 1991, 113, 7994-8005. [CrossRef]

41. Kollmar, C.; Kahn, O. Spin Polarization and Ferromagnetic coupling in metallocenium charge transfer complexes. J. Chem. Phys. 1992, 96, 2988-2997. [CrossRef]

42. Cargill Thompson, A.M.W.; Gatteschi, D.; McCleverty, J.A.; Navas, J.A.; Rentschler, E.; Ward, M.D. Effects of Systematic Variation in Bridging Ligand Structure on the Electrochemical and Magnetic Properties of a Series of Dinuclear Molybdenum Complexes. Inorg. Chem. 1996, 35, 2701-2703. [CrossRef]

43. Hernández-Molina, R.; Mederos, A.; Gili, P.; Domínguez, S.; Lloret, F.; Cano, J.; Julve, M.; Ruiz-Pérez, C.; Solans, X. Dimer species in dimethyl sulfoxide-water $(80: 20 \mathrm{w} / \mathrm{w})$ solution of $N, N^{\prime}$-bis(salicylidene)-m-phenylenediamine $\left(\mathrm{H}_{2}\right.$ sal- $m$-phen) and similar Schiff bases with $\mathrm{Cu}^{\mathrm{II}}, \mathrm{Ni}^{\mathrm{II}}, \mathrm{Co}^{\mathrm{II}}$ and $\mathrm{Zn}^{\mathrm{II}}$. Crystal structure of $\left[\mathrm{Co}_{2}(\mathrm{sal}-m \text {-phen })_{2}\right] \cdot \mathrm{CHCl}_{3}$. J. Chem. Soc. Dalton Trans. 1997, 4327-4334. [CrossRef]

44. Lloret, F.; De Munno, G.; Julve, M.; Cano, J.; Ruiz, R.; Caneschi, A. Spin Polarization and Ferromagnetism in Two-Dimensional Sheetlike Cobalt(II) Polymers: [Co(L) $\left.)_{2}(\mathrm{NCS})_{2}\right]$ (L = Pyrimidine or Pyrazine). Angew. Chem. Int. Ed. 1998, 37, 135-138. [CrossRef]

45. Fernández, I.; Ruiz, R.; Faus, J.; Julve, M.; Lloret, F.; Cano, J.; Ottewaelder, X.; Journaux, Y.; Muñoz, M.C. Ferromagnetic Coupling through Spin Polarization in a Dinuclear Copper(II) Metallacyclophane. Angew. Chem. Int. Ed. 2001, 40, 3039-3042. [CrossRef]

46. Pardo, E.; Morales-Osorio, I.; Julve, M.; Lloret, F.; Cano, J.; Ruiz-García, R.; Pasán, J.; Ruiz-Pérez, C.; Ottewaelder, X.; Journaux, Y. Magnetic Anisotropy of a High-Spin Octanuclear Nickel(II) Complex with a meso-Helicate Core. Inorg. Chem. 2004, 43, 7594-7596. [CrossRef] [PubMed]

47. Pardo, E.; Bernot, K.; Julve, M.; Lloret, F.; Cano, J.; Ruiz-García, R.; Delgado, F.S.; Ruiz-Pérez, C.; Ottenwaelder, X.; Journaux, Y. Spin Control in Ladderlike Hexanuclear Copper(II) Complexes with Metallacyclophane Cores. Inorg. Chem. 2004, 43, 2768-2770. [CrossRef] [PubMed]

48. Foxon, S.P.; Torres, G.R.; Walter, O.; Pedersen, J.Z.; Toflund, H.; Hüber, M.; Falk, K.; Haase, W.; Cano, J.; Lloret, F.; et al. Syntheses, Structures, and Magnetic Properties of Copper(II) Complexes with 1,3-[Bis(2-pyridylmethyl)amino]benzene (1,3-tpbd) as Ligand. Eur. J. Inorg. Chem. 2004, 335-343. [CrossRef]

49. Pascu, M.; Lloret, F.; Avarvari, N.; Julve, M.; Andruh, M. Ferromagnetic Coupling through Spin Polarization in the Hexanuclear [ $\mathrm{Mn}_{3}{ }_{3} \mathrm{Cu}_{3}{ }_{3}$ ] Complex. Inorg. Chem. 2004, 43, 5189-5191. [CrossRef] [PubMed]

50. Foxon, S.P.; Walter, O.; Koch, R.; Rupp, H.; Müller, P.; Schindler, S. Tuning the Magnetic Properties of a Dinuclear Copper Complex: From Ferromagnetic to Antiferromagnetic Coupling. Eur. J. Inorg. Chem. 2004, 344-348. [CrossRef]

51. Paital, A.R.; Mitra, T.; Ray, D.; Wong, W.T.; Ribas-Ariño, J.; Novoa, J.J.; Ribas, J.; Aromí, G. Substituted m-phenylene bridges as strong ferromagnetic couplers for $\mathrm{Cu}^{\mathrm{II}}$-bridge- $\mathrm{Cu}{ }^{\mathrm{II}}$ magnetic interactions: New perspectives. Chem Commun. 2005, 5172-5174. [CrossRef]

52. Cangussu, D.; Pardo, E.; Dul, M.-C.; Lescouëzec, R.; Herson, P.; Journaux, Y.; Pedroso, E.F.; Pereira, C.L.M.; Stumpf, H.O.; Muñoz, M.C.; et al. Rational design of a new class of heterobimetallic molecule-based magnets. Synthesis, crystal structures, and magnetic properties of oxamato-bridged $\mathrm{M}_{3}^{\prime} \mathrm{M}_{2}\left(\mathrm{M}^{\prime}=\mathrm{Li}^{\mathrm{I}}\right.$ and $\mathrm{Mn}^{\mathrm{II}} \cdot ; \mathrm{M}=\mathrm{Ni}^{\mathrm{II}}$ and $\left.\mathrm{Co}^{\mathrm{II}}\right)$ open frameworks with a three-dimensional honeycomb architecture. Inorg. Chim. Acta 2008, 361, 3304-3402.

53. Turba, S.; Walter, O.; Schindler, S.; Nielsen, L.P.; Hazell, A.; McKenzie, C.J.; Lloret, F.; Cano, J.; Julve, M. Syntheses, Structures, and Properties of Copper(II) Complexes of Bis(2-pyridylmethyl) Derivatives of $o_{-}^{-,} m_{-}^{-}$, and $p$-Phenylenediamine and Aniline. Inorg. Chem. 2008, 47, 9612-9623. [CrossRef]

54. Palacios, M.A.; Rodríguez-Diéguez, A.; Sironi, A.; Herrera, J.M.; Mota, A.; Cano, J.; Colacio, E. Enhanced ferromagnetic interaction in metallacyclic complexes incorporating m-phenylenediamidate bridges. Dalton Trans. 2009, 8538-8547. [CrossRef] [PubMed]

55. Ferrando-Soria, J.; Fabelo, O.; Castellano, M.; Cano, J.; Fordham, S.; Zhou, H.-C. Multielectron oxidation in a ferromagnetically coupled nickel(II) triple mesocate. Chem. Commun. 2015, 51, 13381-13384. [CrossRef]

56. Fernandes, T.S.; Vilela, R.S.; Valdo, A.K.; Martins, F.T.; García-España, E.; Inclán, M.; Cano, J.; Lloret, F.; Julve, M.; Stumpf, H.O.; et al. Dicopper(II) Metallacyclophanes with N,N'-2,6-Pyridinebis(oxamate): Solution Study, Synthesis, Crystal Structures, and Magnetic Properties. Inorg. Chem. 2016, 55, 2390-2401. [CrossRef] [PubMed] 